\title{
BLOOD PIPETTE SHAKING MACHINE MARK II
}

BY

\author{
K. C. PARRY
}

From the Medical Division, Atomic Energy Research Establishment, Harwell

(RECEIVED FOR PUBLICATION JUNE 22, 1950)

The blood pipette shaking machine previously reported (Parry and Simmonds, 1950) has been modified to incorporate various improvements. In the new machine (1) the pipettes lie in the same plane and there is greater ease of insertion. (2) The speed of rotary movement has been increased and that of tilting decreased to reproduce

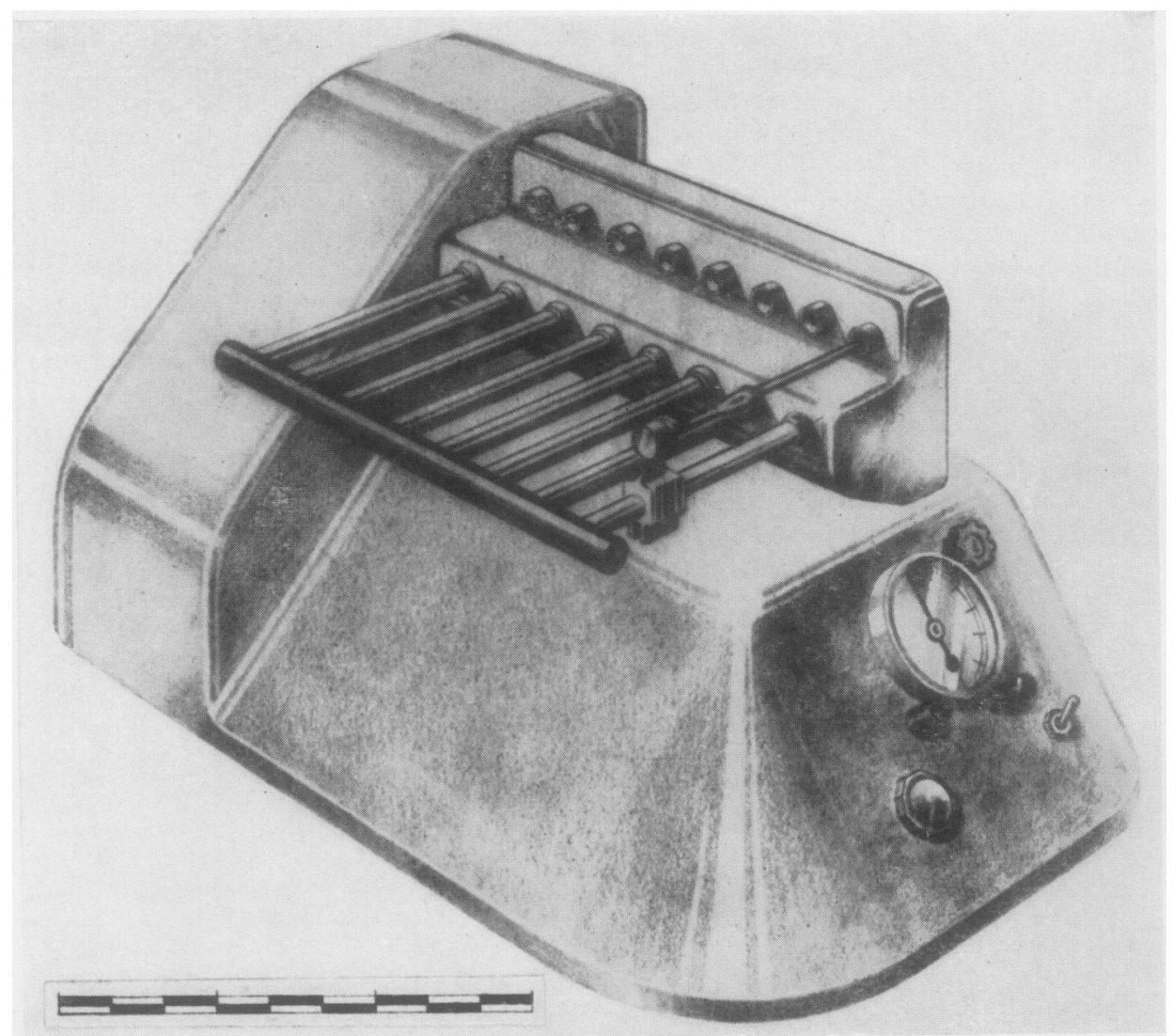

Fig. 1.-Blood pipette shaking machine mark II. 
more exactly the motion imparted to pipettes in the hand shaking method. The speed of tilt is 30 per minute ; the pipettes reciprocate three times to each direction of tilt, so that the number of reciprocal revolutions is now 180 per minute. (3) Eight pipettes can be shaken at the same time. (4) Each pipette holder is numbered to assist in the identification of pipettes. (5) A light indicates when the machine is in circuit. (6) The cost is estimated at less than that of the previous model.

Acknowledgment is made to the Director, Sir John Cockcroft, Atomic Energy Research Establishment, Harwell, for his permission to publish this account.

\section{REFERENCE}

Parry, K. C., and Simmonds, G. E. (1950). J. clin. Path., 3, 164. 